Original Article

\title{
PATIENTS' CONTENTMENT WITH TRANSANAL HEMORRHOIDAL DEARTERIALISATION
}

\author{
Branko Branković $^{1,2}$, Milica Nestorović ${ }^{1,2}$, Goran Stanojević ${ }^{1,2}$, Dejan Petrović ${ }^{1}$, Dragan Mihajlović , Ilija Golubović $^{1}$ \\ ${ }^{1}$ Department for Colorectal Surgery, Clinic for Digestive Surgery, Clinical Centre Niš, Serbia \\ ${ }^{2}$ Faculty of Medicine, University of Niš, Serbia
}

\begin{abstract}
Hemorrhoidectomy was the method of choice for treating grade 3 and 4 hemorrhoids. Due to a large number of complications, a new surgical treatment called transanal hemorrhoidal dearterialization (THD) was introduced. The aim of the study was to evaluate the effect of treatment with THD in patients with hemorrhoids. This study included 70 patients, 48 males and 22 females, who were hospitalized at the Clinical Center Nis in the period from September 2016 to September 2018. Fifteen patients had grade 4 hemorrhoids, 54 were with grade 3, one patient with grade 2. The average duration of the operation was 33.33 minutes, and patients were hospitalized for 1-2 days. We recorded: sex, age, stage, type of anesthesia, duration of surgery, length of stay, patient satisfaction, combinations of THD with other procedures, and surgical complications. In 46 patients, surgery was performed under general anesthesia, in 18 patients in spinal and in 6 patients in local anesthesia with analgesia. In 37 subjects we used THD only, and in 33 we used THD in combination with other methods. We observed the development of complications in 9 patients. Bleeding occurred in 2 patients, pain in 2, and urinary retention in 4, and abscess in 1. The majority of the patients $(62.9 \%)$ were satisfied with this method, $27.1 \%$ were partially satisfied and $10 \%$ were unsatisfied. This method provides a shorter stay in the hospital, low complications rate and is a safe, fast and simple initial surgical option.
\end{abstract}

Key words: hemorrhoids, transanal hemorrhoidal dearterialization, patients'satisfaction, complications.

\section{Introduction}

Hemorrhoidal disease is the most common anorectal pathology and it represents a great socioeconomic and medical problem. It is estimated that $90 \%$ of general population suffers from hemorrhoidal symptoms at least once in their life [1-3]. The rectal bleeding incidence in human population related to hemorrhoidal bleeding is around $20 \%$ per year, compared to all kinds of rectal bleeding [4], while the prevalence of hemorrhoidal disease, according to different studies, varies between $4.4 \%$ and $86 \%$ [5-7].

According to the degree of prolapse, hemorrhoids can be categorized in four groups. Grade I hemorrhoids do not prolapse; grade II prolapses during straining but reduces spontaneously; grade III requires manual reduction; grade IV hemorrhoids reduce rarely or do not at all [8]. A wide range of treatment options for hemorrhoidal diseases is available. The early stages of the disease can usually be treated conservatively with success, while advanced stages require a surgical approach. At present, surgical treatment generally involves the resection of hemorrhoidal cushions, as in conventional hemorrhoidectomy $(\mathrm{CH})$, or prolapse reduction, as in stapled hemorrhoidopexy (SH) [9].

Correspondence to: Branko Branković, M.D., Ph.D.

Faculty of Medicine, 81 Zoran Đinđić Blvd., 18000 Niš, Serbia

Phone: +381638457494

E-mail: mbbrankovic@gmail.com

Received May $7^{\text {th }}, 2019$
Hemorrhoidectomy is considered the standard treatment for symptomatic hemorrhoids, especially for grade III and IV [10]. For years, hemorrhoidectomy, according to Milligan-Morgan and Ferguson, was the golden standard in treating high-grade hemorrhoids [11]. However, open hemorrhoidectomy is connected with postoperative complications like pain, anal stenosis, bleeding, incontinence and even sepsis [12]. Therefore, it was imperative to develop a new, as efficient but less invasive method of treatment [13]. In 1995 a new technique called transanal hemorrhoidal dearterialization (THD), was developed. This procedure aims to reduce arterial blood flow to hemorrhoids $[15,16]$. This technique eliminates hemorrhoidal symptoms by the dearterialization of the terminal hemorrhoid branches of the superior rectal artery. For this procedure an instrument consisting of the proctoscope is used in combination with the Doppler probe for arterial location and ligation. The ligation of blood vessels leads to the decongestion of the hemorrhoidal tissue. Reduced tension enables the regeneration of the connective tissue inside the hemorrhoidal cushion, which results in a lower occurrence of prolapse and relief of the symptoms [17].

The goal of this study was to evaluate the effect of the treatment with transanal hemorrhoidal dearterialization in patients with grade II-IV hemorrhoids and the patients' satisfaction with the procedure.

\section{Material and Methods}

A retrospective study was conducted, which included 70 patients treated at the Department for Colorectal Sur- 
gery of the Clinic for Digestive Surgery, Clinical Centre Nis, Serbia, during the period from September 2016 to September 2018. This study included patients with grade III and IV hemorrhoids, as well as grade II hemorrhoids, in whom the conservative treatment failed. The original technique of THD with or without mucopexy described by Carlo Ratto was used [18].

The patients were contacted by phone 6 months after the surgery. In the course of this study we recorded the following parameters: gender, age, grade of hemorrhoids, duration of hospitalization, type of anesthesia, duration of the surgery, patient satisfaction, the combination of THD with other procedures and surgical complications. A questionnaire prepared in Microsoft Word (Version 14.6.6, 2011, Microsoft Corporation, Redmond, Washington, USA) was used. The collected data were entered into an Excel data base (Version 14.6.6 2011, Microsoft Corporation, Redmond, Washington, USA). The data were analyzed in the statistical package Jandel SigmaStat (Version 2). Chi-square and Fisher's exact test were used for the analysis. The values from $p<0.05$ to $p<0.01$ were considered statistically significant.

\section{Results}

There were 48 male (68.6\%) and 22 female (31.4\%) patients, aging 48.33 on average (32-82). Of the 70 patients, 15 were with grade IV, 54 with grade III and only 1 patient with grade II hemorrhoids (Table 1).

Table 1 Demographical data of the patients

\begin{tabular}{lll}
\hline Data & & N $(\%)$ \\
\hline Sex & Total & $70(100 \%)$ \\
& Male & $48(68.6 \%)$ \\
& Female & $22(31.4 \%)$ \\
Age & Average (range) & $48.33(32-82)$ (years) \\
Grade & I & 0 \\
& II & 1 \\
& III & 54 \\
& IV & 15 \\
\hline
\end{tabular}

The average duration of the surgery was 33.33 minutes, while the patients were hospitalized for 1-2 days. This procedure was conducted under anesthesia, i.e. in 46 patients under general endotracheal anesthesia, in 18 patients spinal anesthesia was used, while in 6 patients local anesthesia with analgosedation was used. In 37 patients only THD was used, while in the other 33 patients THD was combined with other surgical methods (the Milligan-Morgan hemorrhoidectomy, the Ferguson hemorrhoidectomy etc.) (Table 2). Complications were recorded in 9 patients: bleeding occurred in 2 patients, pain in 2 , urinary retention in 4 , and abscess in 1 patient (Table 3).

Postoperative complications are presented in Table 3 . Except for 3 patients, all the others were discharged within 24 hours with no major complaints. Three patients were readmitted for complications (abscess and bleeding). Two patients had postoperative pain and 4 had urinary retention. Six months postoperatively, the majority of the patients $(62.9 \%)$ were highly satisfied with this method, $27.1 \%$ were moderately satisfied, and $10 \%$ were unsatisfied. More than $80 \%$ of the patients would recommend this method to others.

Table 2 Data regarding surgery

\begin{tabular}{|c|c|c|}
\hline \multicolumn{2}{|l|}{ Data } & \multirow{2}{*}{$\frac{\mathrm{N}(\%)}{33.33(\min )}$} \\
\hline $\begin{array}{l}\text { Duration of } \\
\text { the surgery }\end{array}$ & Average & \\
\hline $\begin{array}{l}\text { Period of } \\
\text { hospitalization }\end{array}$ & Average (range) & $\begin{array}{l}1.07(1-2) \\
\text { (day) }\end{array}$ \\
\hline \multirow{3}{*}{$\begin{array}{l}\text { Type of } \\
\text { anesthesia }\end{array}$} & General endotracheal & 46 \\
\hline & Spinal & 18 \\
\hline & Local + analgosedation & 6 \\
\hline \multirow[t]{2}{*}{ Procedure } & THD & 37 \\
\hline & $\begin{array}{l}\text { THD + other (lateral } \\
\text { sphincterotomy, skin tag } \\
\text { removal, fistulotomy, } \\
\text { excision of anal warts, } \\
\text { removal of piles) }\end{array}$ & 33 \\
\hline Complications & & $9(12.86 \%)$ \\
\hline
\end{tabular}

Table 3 Postoperative complications following THD

\begin{tabular}{lc}
\hline Complications & Number of patients \\
\hline Bleeding & 2 \\
Pain & 2 \\
Urinary retention & 4 \\
Abscess & 1 \\
\hline
\end{tabular}

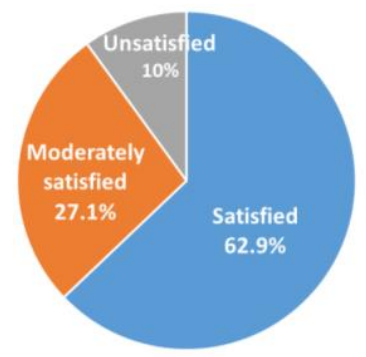

Graph 1 Patients' satisfaction with the procedure in terms of symptom relief

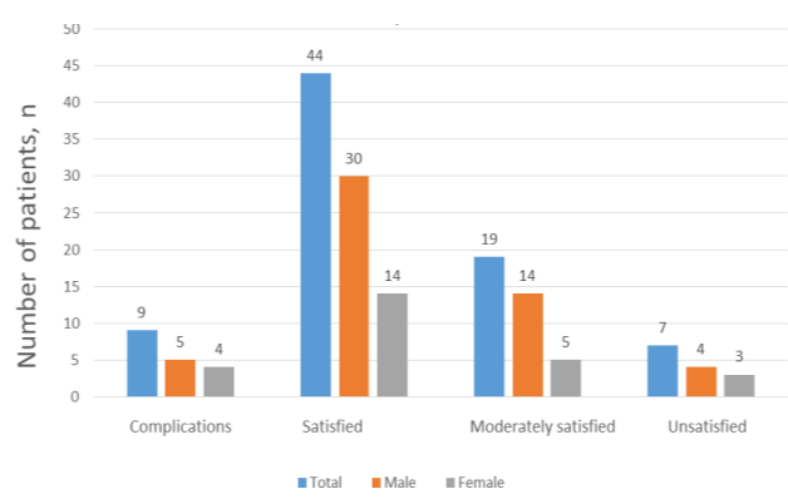

Graph 2 Categorizing patients in terms of complications and satisfaction with the procedure 
Table 4 Review of complications and the applied method in relation to the hemorrhoidal grade (I-IV)

\begin{tabular}{lcrrc}
\hline Hemorrhoids & $\begin{array}{c}\text { Grade } \\
\text { II }\end{array}$ & $\begin{array}{c}\text { Grade } \\
\text { III }\end{array}$ & $\begin{array}{c}\text { Grade } \\
\text { IV }\end{array}$ & p-value \\
\hline Complications, $\mathrm{n}$ & 0 & 8 & 1 & n.s. \\
No complications, $\mathrm{n}$ & 1 & 45 & 15 & n.s. \\
THD, $\mathrm{n}$ & 0 & 28 & 9 & n.s. \\
THD in combination, $\mathrm{n}$ & 1 & 26 & 6 & n.s. \\
\hline
\end{tabular}

The percentage of observations in different categories which define the table of contingency was not significantly different from what is expected in random occurrence (Chi-square, Fisher's exact test).

\section{Discussion}

The surgical treatment of hemorrhoids is taken into consideration when the conservative treatment fails or patients have grade III or IV hemorrhoids and symptomatic hemorrhoidal disease respectively. The methods of conventional hemorrhoidectomy sometimes results in complications, such as urinary retention (2-36\%), bleeding (0.03-6\%), anal stenosis $(0-6 \%)$, infection $(0.5-5.5 \%)$ and incontinence $(2-12 \%)$, as well as postoperative pain $[5,9,10]$. To reduce pain following surgery, techniques of excision have undergone multiple modifications (including diathermia, scissors, laser, Harmonic or Ligasure hemorrhoidectomy). These modifications have not only increased surgical expenses, but have also given poorer results in comparison with usual measures. However, with transanal hemorrhoidal dearterialization not only is postoperative pain reduced but also it rarely has significant complications, such as anal stenosis or incontinence [11].

Besides being minimally invasive, THD is not an excisional procedure. This enables the regeneration of the normal anorectal anatomy; in addition, it or other surgical procedures can be done again in case of recurrence. According to our results, THD can be successfully used in combination with other proctological procedures not influencing the success of the intervention or the satisfaction of patients. In other excisional procedures, a significant resection of the mucous membrane is required; for that reason, the anal canal becomes sensitive to complications, while a combination with other interventions on the anal canal becomes unsuitable.

In this study, complications occurred in $12.85 \%$ of the participants, mostly in the form of urinary retention, pain, bleeding and abscess. Similar rates and types of complications are described in other five large studies which included 388 individuals (Bursics A, et al. 2004, Hungary; Festen S, et al. 2009, Netherlands; Gupta PJ, et al. 2011, India; Infantino A, et al. 2012, Italy; Shuurman JP, et al. 2012, Netherlands) [19]. The results of these studies are encouraging, since these complications are less fre- quent in THD than in conventional hemorrhoidectomies [20-23]. Complications, such as urinary retention, are not really significant since they can be treated with catheterization and efficiently removed on the same day. In our study none of the complications required surgical intervention.

There have been a number of studies on THD which show its early efficacy and safety for all grades of hemorrhoids, and recently THD has been acknowledged by the National Institute for Health and Care Excellence (NICE) as a safe and efficient alternative to conventional hemorrhoidectomies in Great Britain [24]. The recent study on THD for the treatment of grade IV hemorrhoid conducted by Ratto and al. [25] showed the disappearance of symptoms in $94 \%$ of the patients, while only $6 \%$ required additional surgeries. Similar results were obtained in our study as well. This method was successful in $60 \%$ of the patients with grade IV hemorrhoids.

Due to promising results and considerably low rate of recurrence, THD meets all criteria for coming up with patients' expectations. In the studies conducted to evaluate the success of the THD procedure, patients' satisfaction has had a great role [26]. In 2010, Tempel and al. [27] carried out a study on patients' satisfaction after THD and found out that $91.5 \%$ of the patients were satisfied with the procedure because it had helped with the disappearance of the symptoms. It has been equally well evaluated by surgeons [28]. In our study $62.9 \%$ of the participants were satisfied with this procedure.

The presence of complications after THD could be considered as failure of this method. Taking into consideration this failure, we can conclude that the success of this procedure was $87.14 \%$. A high rate of success of THD can be attributed to the fact that in all patients a technique of distal dearterialization, the DDD (Dopplerguided distal dearterialization) modification, has been used [18]. It is important to point out that the procedure can be successfully repeated several times, and that the adequate choice of patients is crucial for its success.

A drawback of this study is its retrospective character since it was not possible to establish with a certainty in which patients mucopexy was performed, so it was not possible to conclude if the success rate of THD was additionally increased.

\section{Conclusion}

It is suggested that THD has fewer postoperative complications and shorter recovery due to reduction of postoperative pain than other conventional surgery. Patients treated with THD experience faster recovery. High satisfaction rate, tolerable rate of complications, shorter leave of absence and reduced level of postoperative pain suggest that this is a safe, fast and simple surgical option. 


\section{References}

1. Zampieri N, Castellani R, Andreoli R, Geccherle A. Longterm results and quality of life in patients treated with hemorrhoidectomy using two different techniques: ligasure versus transanal hemorrhoidal dearterialization. Am J Surg 2012; 204:684-688.

2. Johanson JF, Sonnenberg A. The prevalence of hemorrhoids and chronic constipation. an epidemiologic study. Gastroenterology 1990; 98:380-386.

3. Madoff RD, Fleshman JW. Clinical Practice Committee, American Gastroenterological Association American Gastroenterological Association technical review on the diagnosis and treatment of hemorrhoids. Gastroenterology 2004; 126:1463-1473.

4. Fijten GH, Blijham GH, Knottnerus JA. Occurrence and clinical significance of overt blood loss per rectum in the general population and in medical practice. Br J Gen Pract 1994; 44:320-325.

5. Johanson JF, Sonnemberg A. The prevalence of hemorrhoids and chronic constipation. An epidemiological study. Gastroenterology 1990; 98:380-386.

6. Bleday R, Pena JP, Rothenberger DA, Goldberg SM, Buls JG. Symptomatic hemorrhoids: current incidence and complications of operative therapy. Dis Colon Rectum 1990; 35:477-481.

7. Haas PA, Haas GP, Schmaltz S, Fox TA. The prevalence of hemorrhoids. Dis Colon Rectum 1983; 26:435-439.

8. Sardinha TC, Corman ML. Hemorrhoids. Surg Clin North Am 2002; 82:1153-1167.

9. Gravie JF, Lehur PA, Huten N, et al. Stapled hemorrhoidopexy versus Milligan-Morgan hemorrhoidectomy: a prospective, randomized, multicenter trial with 2-year postoperative follow up. Ann Surg 2005; 242:29-35.

10. Chen HL, Woo XB, Cui J, Chen CQ, Peng JS. Ligasure versus stapled hemorrhoidectomy in the treatment of hemorrhoids: a meta-analysis of randomized control trials. Surg Laparosc Endosc Percutan Tech 2014; 24:285-289.

11. Picchio M, Palimento D, Attanasio U, Renda A. Stapled vs open hemorrhoidectomy: long-term outcome of a randomized controlled trial. Int J Colorectal Dis 2006; 21:668-669.

12. $\mathrm{Xu} \mathrm{L}$, Chen $\mathrm{H}$, Lin $\mathrm{G}, \mathrm{Ge} \mathrm{Q}$. Ligasure versus Ferguson hemorrhoidectomy in the treatment of hemorrhoids: a metaanalysis of randomized control trials. Surg Laparosc Endosc Percutan Tech 2015; 25:106-110

13. Maloku H, Gashi Z, Lazovic R, Islami H, Juniku-Shkololli A. Laser hemorrhoidoplasty procedure vs open surgical hemorrhoidectomy: a trial comparing 2 treatments for hemorrhoids of third and fourth degree. Acta Inform Med 2014; 22:365-367.

14. Morinaga K, Hasuda K, Ikeda T. A novel therapy for internal hemorrhoids: ligation of the hemorrhoidal artery with a newly devised instrument (Moricorn) in conjunction with a Doppler flowmeter. Am J Gastroenterol 1995; 90:610-613.

15. Hoyuela C, Carvajal F, Juvany M, et al. HAL-RAR (Doppler guided hemorrhoid artery ligation with recto-anal repair) is a safe and effective procedure for hemorrhoids. Results of a prospective study after two-years follow-up. Int $\mathrm{J}$ Colorectal Dis 2016; 28:39-44.

16. Chayama K, Tsubota A, Arase Y, et al. Genotype, slow decrease in virus titer during interferon treatment and high degree of sequence variability of hypervariable region are indicative of poor response to interferon treatment in patients with chronic hepatitis type C. J Hepatol 1995; 23:648-653.

17. Ratto C, Parello A, Veronese E, et al. Doppler-guided transanal hemorrhoidal dearterialization for hemorrhoids: results from a multicentre trial. Colorectal Dis 2015; 17(1):O10-9.

18. Ratto C, Donisi L, Parello A, Litta F, Zaccone G, De Simone V. 'Distal Doppler-guided dearterialization' is highly effective in treating hemorrhoids by transanal hemorrhoidal dearterialization. Colorectal Dis 2012; 14(11):e786-9.

19. Liu H, Yang C, Chen B, Wu J, He H. Clinical outcomes of Doppler-guided hemorrhoidal artery ligation: a meta-analysis Int J Clin Exp Med 2015; 8(4):4932-4939.

20. Pescatori M, Gagliardi G. Postoperative complications after procedure for prolapsed hemorrhoids $(\mathrm{PPH})$ and stapled transanal rectal resection (STARR) procedures. Tech Coloproctol 2008; 12:7-19.

21. Faucheron JL, Voirin D, Abba J. Rectal perforation with lifethreatening peritonitis following stapled haemorrhoidopexy. $\mathrm{Br}$ J Surg 2012; 99:746-753.

22. Festen S, Van Hoogstraten MJ, Van Geloven AA, Gerhards MF. Treatment of grade III and IV hemorrhoidal disease with PPH or THD. A randomized trial on postoperative complications and short-term results. Int J Colorectal Dis 2009; 24:1401-1405.

23. Sajid MS, Parampalli U, Whitehouse P, Sains P, McFall MR, Baig MK. A systematic review comparing transanal hemorrhoidal dearterialisation to stapled haemorrhoidopexy in the management of hemorrhoidal disease. Tech Coloproctol 2012; 16:1-8.

24. Pucher PH, Sodergren MH, Lord AC, Darzi A, Ziprin P. Clinical outcome following Doppler-guided hemorrhoidal artery ligation: a systematic review. Colorect Dis 2013; 15:e284-e294.

25. Ratto C, Giordano P, Donisi L, Parello A, Litta F, Doglietto BG. Transanal hemorrhoidal dearterialization (THD) for selected fourth-degree hemorrhoids. Tech Coloproctol 2011; 15:191.

26. Denoya PI, Fakhoury M, Chang K, Fakhoury J, Bergamaschi R. Dearterialization with mucopexy vs hemorrhoidectomy for grade III or IV hemorrhoids: short-term results of a double-blind randomized controlled trial. Colorectal Dis 2013; 15:1281-1288.

27. Tempel MB, Pearson EG, Page M, et al. Survey of patient satisfaction after Doppler-guided transanal hemorrhoidal dearterialization performed in ambulatory settings. Tech Coloproctol 2014; 18(6):607-610.

28. LaBella GD, Main WP, Hussain LR. Evaluation of transanal hemorrhoidal dearterialization: a single surgeon experience. Tech Coloproctol 2015; 19(3):153-157. 